\title{
Unusual optic disc infarction in a case of arteritic anterior ischaemic optic neuropathy (AAION)
}

\author{
Dawn KA $\underline{\text { Lim }}^{1}$, MRCP, MMed, Sunny $\underline{\text { Shen }}^{1}$, FRCSEd, Issam Al Jejah ${ }^{2}$, MD, James $F \underline{\text { Cullen }}{ }^{1}$, FRCS
}

\begin{abstract}
Herein, we report another case of arteritic anterior ischaemic optic neuropathy from Singapore, in which the initial optic disc swelling was extreme and the sequential disease resolved because the patient was already on maximum treatment. As the management of this biopsy-proven giant cell arteritis case was complicated by the presence of a number of other medical conditions, including end-stage renal failure, monitoring of the response to treatment proved problematic.
\end{abstract}

Keywords: arteritic anterior ischaemic optic neuropathy, corticosteroid treatment management, second eye involvement, temporal artery biopsy

\section{INTRODUCTION}

Giant cell arteritis (GCA) is a type of vasculitis, which affects large- and medium-sized vessels, with a predilection to involve the external carotid and its branches, especially the superficial temporal vessels, hence its original name 'temporal arteritis'. The condition occurs in classical and occult forms, ${ }^{(1)}$ and it has maximum incidence in the northern hemisphere; the annual frequency in Scotland was reported to be 4.2 cases per 100,000 population aged over 50 years. ${ }^{(2)}$ GCA, however, is extremely rare in South East Asia. In a report published in 2010, only eight biopsy-proven cases were encountered in the Singapore National Eye Centre over a period of seven years. ${ }^{(3)}$

Hayreh et al ${ }^{(1)}$ reported that $21.2 \%$ of their patients with GCA and visual loss did not have any systemic symptoms; the authors thus categorised these patients as having the occult form of the disease. Visual loss in over $90 \%$ of occult GCA cases is due to a severe acute arteritic anterior ischaemic optic neuropathy (AAION), where the vascular occlusion involves the posterior ciliary arteries that supply the optic nerve head; ${ }^{(4)}$ contrarily, these vessels arise from the branches of the internal carotid artery.

Herein, we report a further case of occult GCA from Singapore, in which the initial optic disc appearance was possibly unique and quite dissimilar from those described in our earlier cases; ${ }^{(3)}$ this case is also unlike any of those illustrated in Hayreh's book. ${ }^{(5)}$

\section{CASE REPORT}

A 58-year-old Chinese woman who was already admitted in hospital for several medical problems (the most immediate being bilateral lower limb ischaemia) was referred to the NeuroOphthalmology Service of the Singapore National Eye Centre on 10 July 2013 because she experienced a sudden loss of vision in her right eye. The loss of vision had persisted for three days. She was on treatment for long-standing hypertension, dyslipidaemia, ischaemic heart disease and atrial fibrillation; she also had endstage renal failure, for which she was receiving haemodialysis. There was no immediate history of fever, weight loss, scalp pain, jaw claudication or other constitutional symptoms; there was also no evidence of any autoimmune disorder.
On examination, we found that the patient's right eye vision was reduced to bare perception of hand movements. She had a relative afferent pupil defect, and the significant finding was a right pale swollen optic disc with a retinal infarct in the upper temporal arcuate area (Fig. 1); the retinal arterioles also appeared attenuated (Fig. 1a). Her left eye was essentially normal with 6/12 vision associated with nuclear sclerosis cataract; the optic disc of the left eye was normal at this stage. A provisional diagnosis of occult GCA associated with AAION was made, and the patient was immediately started on oral prednisolone $1 \mathrm{mg} /$ $\mathrm{kg}$ /day (i.e. $60 \mathrm{mg} /$ day). A temporal artery biopsy was scheduled for the following day. The optic disc swelling was unusual and extreme even for $\mathrm{AAION}$, and the lesion in the retina was considered to be due to a cilioretinal artery infarct.

The patient's full blood count showed leucocytosis, with an elevated total white cell count of $12.75 \times 10^{9} / \mathrm{L}$. The erythrocyte sedimentation rate (ESR) was $140 \mathrm{~mm} / \mathrm{hr}$, the C-reactive protein (CRP) concentration was 90.8 (normal range $0.2-9.1$ ) $\mathrm{mg} / \mathrm{L}$, and there was no thrombocytosis. As the patient's pre-corticosteroid workup was positive for latent tuberculosis, prophylactic isoniazid was prescribed in addition to the multiple medications, which the patient was already taking for her other medical conditions.

Temporal artery biopsy revealed a nodular thickened artery. Histological examination of that artery demonstrated considerable calcification in the vessel, and thickening of the media and intima with monocytic inflammatory cells (Fig. 2a). There was fragmentation within the elastic lamina with inflammatory infiltrate, including the presence of giant cells (Fig. 2b); these findings hence being supportive of a diagnosis of GCA.

As expected, there was no visual improvement in the affected eye when the disc swelling gradually diminished (Fig. 1b). However, a week later, the fellow eye showed signs of impending AAION, with sectoral disc swelling superotemporally (Fig. 3a) and a corresponding inferonasal field defect on the Goldmann visual field. This happened even though the patient was on a high dose of oral corticosteroids (i.e. $1 \mathrm{mg} / \mathrm{kg} /$ day). The disc swelling in the second eye gradually resolved over the next six weeks (Fig. 3b),

${ }^{1}$ Neuro-Ophthalmology Service, Singapore National Eye Centre, ${ }^{2}$ Department of Pathology, Singapore General Hospital, Singapore

Correspondence: Dr James F Cullen, Senior Consultant, Neuro-Ophthalmology Service, Singapore National Eye Centre, 11 Third Hospital Avenue, Singapore 168751. jbarrycullen@yahoo.com 

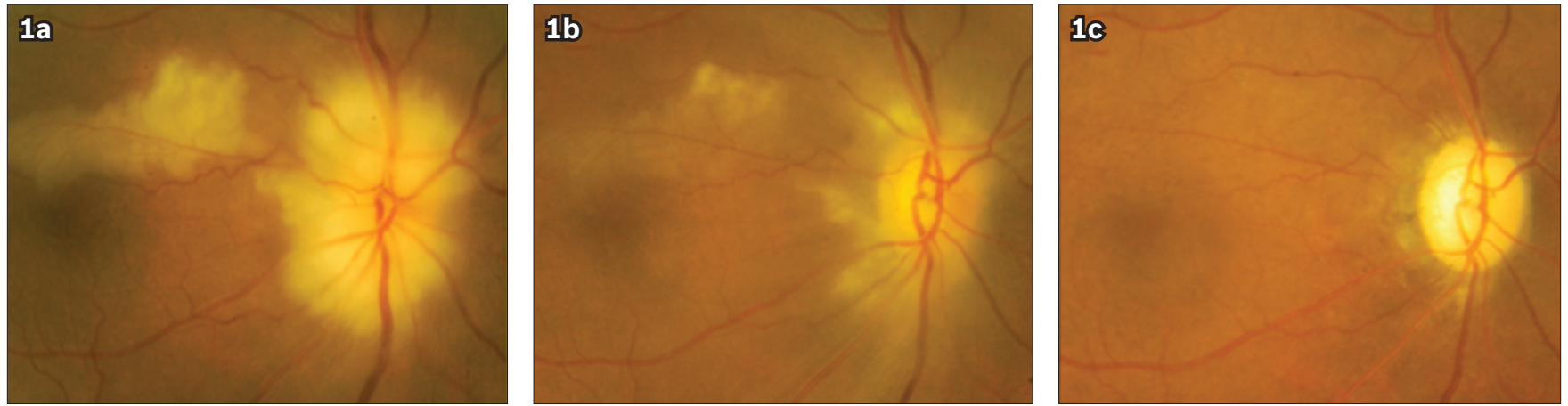

Fig. 1 Fundus photographs of the right eye show (a) a pale swollen disc in association with a cilioretinal artery occlusion with narrow retinal arterioles noted; (b) resolving disc swelling and cilioretinal artery occlusion a week following the diagnosis; and (c) a flat and pale disc without cupping three months from the time of diagnosis.
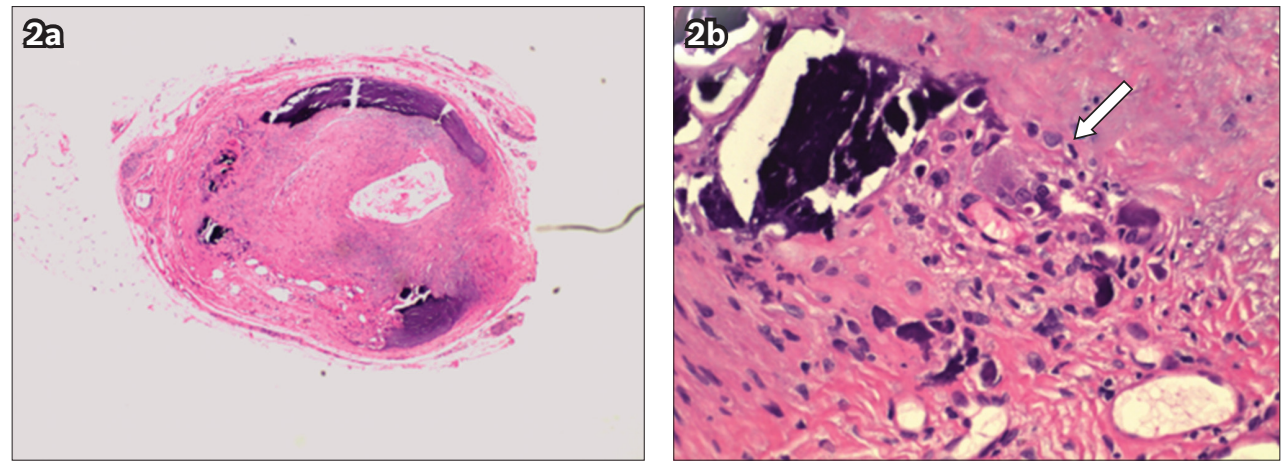

Fig. 2 Photomicrograph of (a) the cross-section of the biopsied superficial temporal artery shows thickening of the media and intima with monocytic inflammatory cells and considerable calcification (Haematoxylin \& eosin, $\times 4$ ); and (b) a section of the arterial wall shows giant cell complex (arrow) (Haematoxylin \& eosin, $\times 20$ ).
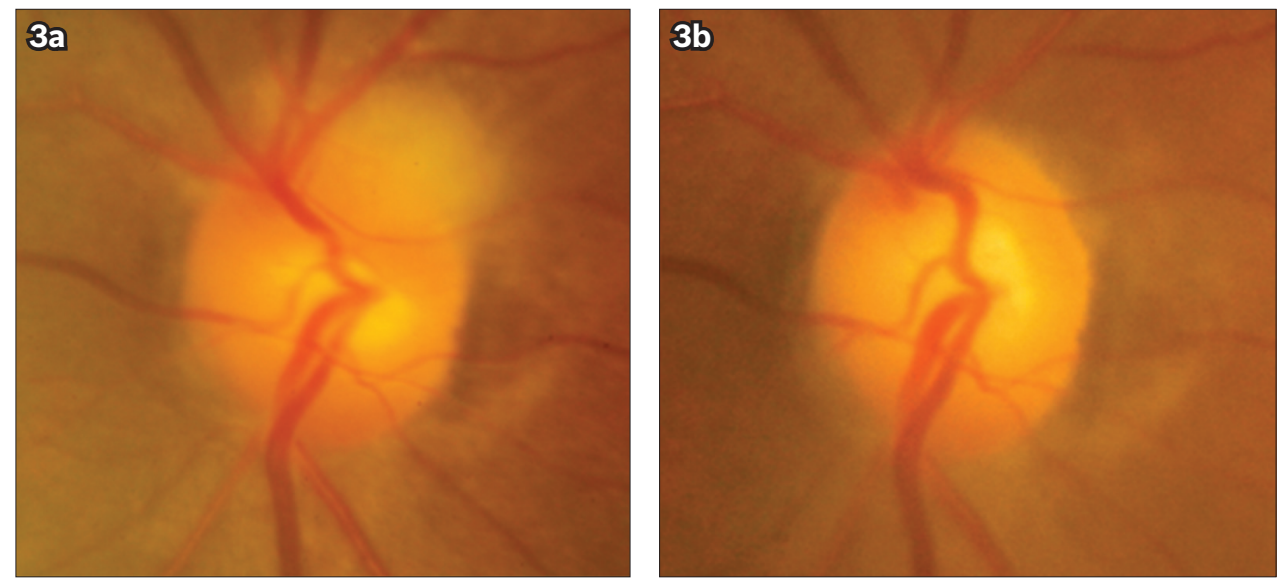

Fig. 3 Fundus photographs show (a) involvement of the fellow eye one week from the time of diagnosis, with sectoral superotemporal disc swelling indicative of impending arteritic anterior ischaemic optic neuropathy; and (b) resolution of the disc swelling in the fellow eye six weeks later.

with vision maintained at 6/12, no development of disc pallor and no change in the inferior nasal visual field defect.

A very gradual taper of the patient's corticosteroids was made over two months, with daily monitoring of her visual status. Only after nearly five months was she discharged from the hospital with a prescription for $10 \mathrm{mg}$ prednisolone daily. At this time, her right eye vision was counting fingers (in the upper temporal quadrant only); her left eye vision remained at 6/12. The patient's right eye disc was flat and very pale without cupping (Fig. 1c), while the left eye disc was normal and pink with no swelling or cupping (Fig. 3b). The patient died unexpectedly at home one week following her discharge from the hospital.

\section{DISCUSSION}

Our case report highlights that patients with other serious medical conditions (our patient had many) can still develop GCA. Clinicians should be aware of this, because GCA, if unrecognised and untreated, can result in permanent bilateral blindness. Second eye involvement commonly occurs within a week, (2) as was the situation in the present case. Fortunately, our patient's sequential 
ischaemic process was mild and prevented from worsening. In fact, it resolved as she was receiving high dose corticosteroid treatment.

The appearance of the right optic disc in our patient was unusual. It showed more than usual swelling and pallor, suggesting complete infarction. There was also attenuation of the retinal arterioles, suggesting additional involvement of the central retinal artery, which supplies the surface/retinal layer of the optic nerve head/disc. The deeper layers of the optic nerve head/disc (i.e. prelaminar, laminar and retrolaminar) are supplied by the posterior ciliary vessels, which are preferentially involved in occult GCA. ${ }^{(5)}$

In GCA, the central retinal artery is usually not affected within the optic nerve or eye, but in the orbit where it can originate from a common trunk with one of the posterior ciliary arteries. ${ }^{(6)}$ In our case, there was clear attenuation of the retinal arterioles at outset (Fig. 1a), implying that there may have been some additional compromise in the retinal centripetal vessels supplying the surface layer of the nerve head. The infarct seen in the patient's right superior temporal retina was due to occlusion of a cilioretinal vessel, which also arises from the ciliary circulation.

As our patient had end-stage renal failure and was on haemodialysis, the ESR was not the ideal test for monitoring her response to treatment because it is known to be chronically elevated in end-stage renal failure. ${ }^{(7)}$ Hence, CRP levels played a critical role in our management of the patient. ${ }^{(8)}$ The patient's CRP level fell to $3 \mathrm{mg} / \mathrm{L}$ after one week, while her ESR only fell to $55 \mathrm{~mm} / \mathrm{hr}$ after a month of treatment. Prior to discharge, her ESR was $54 \mathrm{~mm} / \mathrm{hr}$ and her CRP level was $42.6 \mathrm{mg} / \mathrm{L}$.

In conclusion, it is important for clinicians to note that, although GCA and its occult variety have not been frequently diagnosed in South East Asia, it should still be considered in the differential diagnosis of otherwise unexplained severe loss of vision in elderly patients.

\section{REFERENCES}

1. Hayreh SS, Podhajsky PA, Zimmerman B. Occult giant cell arteritis: ocular manifestations. Am J Ophthalmol 1998; 125:521-6.

2. Jonasson F, Cullen JF, Elton RA. Temporal arteritis. A 14-year epidemiological, clinical and prognostic study. Scott Med J 1979; 24:111-7.

3. Cullen JF, Chan BM, Wong CF, Chew WC. Giant cell (temporal) arteritis in Singapore: an occult case and the rationale of treatment. Singapore Med J 2010; 51:73-7.

4. Cullen JF. Temporal arteritis 50 years on. Br J Ophthalmol 2009; 93:833-4.

5. Hayreh SS. Ischemic Optic Neuropathies. Heidelberg: Springer, 2011: 199-221.

6. Hayreh SS. The ophthalmic artery: III. Branches. Br J Ophthalmol 1962; 46:212-47.

7. Bathon J, Graves J, Jens P, Hemrick R, Mayes M. The erythrocyte sedimentation rate in end-stage renal failure. Am J Kidney Dis 1987; 10:34-40

8. Kermani TA, Schmidt J, Crowson CS, et al. Utility of erythrocyte sedimentation rate and C-reactive protein for the diagnosis of giant cell arteritis. Semin Arthritis Rheum 2012; 41:866-71. 